Another possible reason for the rise in titre of tumour antibody and its improved detection after tumour removal is the fact that manipulation of tumours at operation may lead to release of live tumour cells into the circulation, and the neoantigens of the released tumour cells could act as further stimulus for antibody production. Since most malignant tumours undergo some degree of necrosis, implying that intracellular antigens are released, it may be that neoantigens from necrotic tumour cells are not as immunogenic as those of live or whole tumour cells. The demonstration by Ikonopisov et al. (1970), that of 13 patients with malignant melanoma in whom antibodies were not detectable the subcutaneous injection of irradiated autologous tumour cells resulted in the development of tumour antibodies in nine, may be supportive evidence for this suggestion. In the cases reported by Ikonopisov et al. (1970) the antibody response was also transient, varying from six days in patients with widespread disease to 10 to 14 days in those whose tumour spread was limited to the regional lymph nodes.

No significant difference has been observed in the course of the disease between the patients who had detectable antibodies and the antibody-negative ones. Two of the patients who had demonstrable tumour antibody died 6 and 12 months after operation respectively. The other three are still alive at the time of writing and have survived 29,21 , and 15 months since operation. Of the 31 antibody-negative patients, 14 have died, their postoperative survival time ranging from 1 to 25 months (mean 9.8 months). The remaining 17 antibodynegative patients, who are still alive, have a postoperative survival time ranging from 11 to 29 months (mean 19 months).
Thus while it cannot be said that antibody responses in the five positive cases have altered the course of the disease for the better, there has been no evidence suggesting that the antibodies detected enhanced the growth of any residual tumour in these patients. From the pattern of antibody responses detected in this study we conclude that in vivo reaction between tumour neoantigens and tumour antibodies could be a reason for the low frequency of detection of circulating tumour antibodies in man.

We wish to thank the Research Grants Committee of the United Manchester Hospitals for supporting this project.

\section{References}

Alexander, P. (1970). British Medical fournal, 4, 484.

Dore, J. F., et al. (1967). Lancet, 2, 1396.

Fairley, G. H. (1969). British Medical fournal, 2, 467.

Fairley, G. H. (1970). British Medical fournal, 4, 483.

Gold, P., and Freedman, S. O. (1965). Fournal of Experimental Medicine, $122,467$.

Graham, J. B., and Graham, R. M. (1955). Cancer, 8, 409.

Hodkinson, M., and Taylor, G. (1969). British fournal of Cancer, 23, 510.

Ikonopisov, R. L., et al. (1970). British Medical fournal, $2,752$.

Klein, G. (1970). British Medical fournal, 4, 418 .

Lewis, M. G. (1967) Lancet, 921.

Lewis, M. G., et al. (1969). British Medical fournal, 3, 547.

Lewis, M. G., et al. (1969). British Medical fourn

Mathé, G. (1969). British Medical fournal, 4, 7.

Mathé, G. (1970). British Medical fournal, 4, 487.

Southam, C. M. (1965). European fournal of Cancer, 1, 173.

Taylor, G., and Odili, J. L. (1970). British Fournal of Cancer, 24, 447.

Wilson, R. H., Byers, E. H., Schram, A. C., and Shields, L. F. (1963). In Conceptual Advances in Immunology and Oncology, p. 521. New York,

Woodruff, M. (1970). British Medical fournal, 4, 486.

\title{
Clinical Evaluation of Perhexiline Maleate in Patients with Angina Pectoris
}

\author{
C. J. BURNS-COX, K. P. CHANDRASEKHAR, \\ C. D. M. QUINLAN, J. RUSSELL REES \\ H. IKRAM, T. H. PEIRCE, J. PILCHER,
}

British Medical fournal, 1971, 4, 586-588

\section{Summary}

This paper reports a double-blind trial of a new antianginal drug, perhexiline. Fifty-five patients suffering from angina pectoris were studied for periods of 12 or 24 weeks in a cross-over comparison against a placebo in four centres in the United Kingdom and Ireland. Perhexiline was effective in most patients as judged by reducing the number of anginal attacks in $84 \%$ and the consumption of glyceryl trinitrate tablets in $64 \%$. The major side effect, dizziness, noted in one-third of the patients, may be dose/body-weight related. Perhexiline

Bristol General Hospital, Bristol BS1 6SY

C. J. BURNS-COX, M.B., B.S., M.R.C.P., Senior Medical Registrar

J. RUSSELL REES, M.D., M.R.C.P., Consultant Physician

United Sheffield Hospitals and Sheffield Regional Hospital Board K. P. CHANDRASEKHAR, M.D., M.R.C.P.ED., Senior Medical Registrar J. PILCHER, M.B., B.CHIR., M.R.C.P., Senior Medical Registrar

Charing Cross Hospital, London WC2N 4DZ

H. IKRAM, M.B., CH.B., M.R.C.P., Senior Medical Registrar

Adelaide Hospital, Dublin C.8

T. H. PEIRCE, M.B., B.CH., B.A.o., Medical Registrar

C. D. M. QUINLAN, M.B., B.CH., M.R.C.P., Senior Medical Registrar

is a valuable new agent for the treatment of patients with angina, especially those who do not respond to other antianginal agents.

\section{Introduction}

Perhexiline maleate is a new antianginal drug which is related to hexadylamine, a known coronary vasodilator. Its chemical formula is:

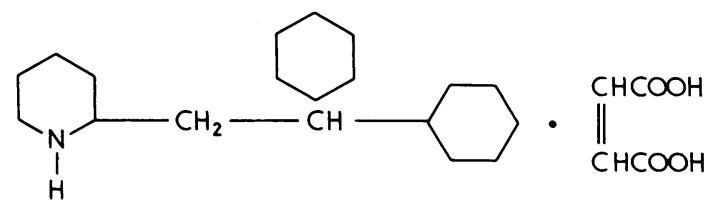

Perhexiline's actions in animals have been described by Hudak et al. (1970) and by Cho et al. (1970). These are: (1) systemic and coronary arterial vasodilation, (2) increase in coronary arterial and venous blood flow, (3) slowing of the heart rate, and (4) increase in pulmonary compliance.

Studies with perhexiline in man have been done in the United States and Brazil (Hirshleifer, 1969; Martins de Oliveira 
and de Almeida Amado, 1970; Winsor, 1970; Lyon et al., 1971). We report here the results of a multicentre double-blind trial in angina pectoris undertaken in the United Kingdom and Ireland.

\section{Patients and Methods}

Fifty-five patients ( 6 women and 49 men) with typical angina pectoris agreed to be studied in four centres. Their mean age was 54.4 (range 31-67) years. For inclusion in the trial patients had to have had typical angina pectoris for at least six months occurring five or more times weekly. Patients with heart failure, a diastolic blood pressure of $110 \mathrm{~mm} \mathrm{Hg}$ or more, myocardial infarction in the preceding six months, or other illnesses such as thyroid disease or anaemia were excluded. Patients were observed for four weeks before entry to the trial. During this time they recorded the frequency of attacks of angina together with their glyceryl trinitrate consumption. All other antianginal drugs were withheld during this time and during the trial proper.

The trial consisted of two periods of either four weeks (Bristol, Dublin, and London) or eight weeks (Sheffield). Perhexiline tablets (200 mg twice daily) or placebo tablets similar in appearance and taste were randomly allocated. Patients changed from active drug to placebo, or vice versa, at the completion of the first period. Neither patient nor investigator was aware, at the time, of the identity of the tablets given, and supplies were allocated so that about the same number of patients had active or placebo tablets first.

Patients were seen and examined at four-weekly intervals. During the trial they continued to record anginal attacks, glyceryl trinitrate consumption, and other symptoms or unusual events. Blood, urine, and electrocardiographic examinations were done at each visit. Chest $x$-ray films were taken at the beginning and end of the study.

\section{Results}

Thirty-seven patients entered the four-week cross-over studies and 33 completed the course, and 18 entered the eight-week study and 12 completed the course. The Table shows the response of patients to placebo tablets and to perhexiline.

Clinical Response to Perhexiline Maleate Compared with Response to Placebo

\begin{tabular}{|c|c|c|c|c|}
\hline & $\begin{array}{l}\text { No. of } \\
\text { Cases }\end{array}$ & $\begin{array}{l}\text { Fewer Attacks } \\
\text { on Perhexiline } \\
\text { than on Placebo }\end{array}$ & $\begin{array}{l}\text { Reduction } \\
\text { by } 50 \% \text { or } \\
\text { more }\end{array}$ & $\begin{array}{c}\text { Same No. } \\
\text { or more } \\
\text { Attacks }\end{array}$ \\
\hline \multirow{2}{*}{$\begin{array}{l}\text { Anginal atracks } \\
\begin{array}{c}\text { Glyceryl trinitrate } \\
\text { consumption }\end{array}\end{array}$} & 45 & $38 \quad(84 \%)$ & $20 \quad(44 \%)$ & $7(16 \%)$ \\
\hline & 45 & $29 \quad(64 \%)$ & $20 \quad(44 \%)$ & $16(36 \%)$ \\
\hline
\end{tabular}

Eighty-four per cent. of the patients had fewer anginal attacks on active perhexiline than on placebo and $64 \%$ used less glyceryl trinitrate; with the Wilcoxon matched-pairs signed-ranks test this difference was highly significant $(\mathrm{P}<0.001)$. In slightly less than half the patients the reduction of attacks and of glyceryl trinitrate consumption was $50 \%$ or more. By contrast, comparison of placebo with no drug (fourweek pretreatment periods) showed no significant reduction either in the frequency of anginal attacks or the amount of glyceryl trinitrate consumption. Response was seen in most patients within 48 hours of active therapy but in some response was not evident until several days had passed.

A loss of weight was noted in patients while taking perhexiline, in contrast to control or to placebo periods; this may be due to a diuretic effect of perhexiline. Lyon et al. (1971) reported that many of their patients had polyuria when taking perhexiline and that this symptom was accompanied by weight loss apparently due to diuresis.

\section{SIDE EFFECTS}

Twenty-five patients had one or more side effects while taking active tablets, and five had side effects on placebo. These side effects were severe enough to cause withdrawal from the trial in seven cases. One patient withdrew on placebo. All side effects subsided within 48 hours of discontinuing the drug or placebo. In the remaining 18 patients side effects were not severe and subsided spontaneously on continued administration.

The most common side effect on perhexiline was dizziness, which was responsible for withdrawal from the trial of three patients. The next most common side effect was nausea with vomiting. Less frequent symptoms were lethargy, tremor and incoordination, diplopia, and palpitations. One elderly patient was withdrawn because of mental confusion and another left the trial having developed a rash, subsequently diagnosed as pityriasis rosea. The weights on entering the trial of those patients with side effects on perhexiline were compared by the Mann Whitney $U$ test with those without side effects. Those with side effects weighed significantly less $(P<0.005)$.

No abnormalities due to the drug were observed on electrocardiography or chest $x$-ray examination. Tests of haematological and renal function were normal. Slightly raised serum aspartate aminotransferase (SGOT) levels were observed in some patients at three of the four centres; no patient was unwell and other liver function tests remained normal. These biochemical abnormalities will be discussed in a future publication on long-term studies.

Two patients died during the study. Both were on active drug at the time. The cause of death in each case was myocardial infarction, and perhexiline was not thought to be implicated.

\section{Discussion}

Drugs used in patients with angina have been assessed in various ways. Glyceryl trinitrate consumption has been used as an objective criterion and has been found to correlate well with frequency of anginal attacks (Gillam and Prichard, 1965). Other workers, particularly Wilson et al. (1969), thought that emphasis should also be placed on patient preference and the distance achieved before angina occurs. Others again lay emphasis on E.C.G. changes, particularly on exercise, but there is still disagreement about the significance of these changes, and standardization of the tests is difficult. In this study we used two criteria-glyceryl trinitrate consumption and frequency of anginal attacks. The results with perhexiline compare favourably with those reported on propranolol (Gillam and Prichard, 1965; Keelan, 1965), practolol (George et al., 1970), and oxprenolol (Wilson et al., 1969). More patients were studied by us as a result of running trials on the same lines at three centres in England and one in Ireland. Remarkably uniform results were reported independently from each centre as regards the effect of the drug on angina but there was some variation in the incidence of side effects.

Experimentally perhexiline has been shown to have a vasodilator action on coronary and other arterioles. Hudak et al. (1970) showed that it was more effective than glyceryl trinitrate in increasing coronary blood flow in open chest dogs, and, unlike glyceryl trinitrate, coronary flow was maintained above control values after perhexiline in high dosage, despite a $40 \%$ fall in mean arterial blood pressure. Winsor (1970) and Grupp et al. (1970) found that perhexiline significantly reduced the tachycardia of exercise in man. Unlike propranolol perhexiline does not lower heart rates at rest and may be unique in this respect. Coronary flow is maximal in diastole, and any drug that reduces exercise tachycardia would be expected to be beneficial on this 
account as well as by reducing myocardial oxygen consumption. This may explain the effectiveness of the drug. Perhexiline does not block beta-receptors, and though it has been shown expetimentally to have a quinidine-like action in rat, rabbit, and dog hearts it is difficult to reconcile this action with reduction of exercise tachycardia alone.

The results in this trial are similar to those reported previously on perhexiline in the United States (Hirshleifer, 1969; Winsor, 1970; Lyon et al., 1971). All trials indicate that perhexiline is effective in angina pectoris-indeed patients in this study had relief from angina when other drugs, including beta-blockers, had failed.

The commonest side effect in all trials has been vertigo or dizziness, with a lesser incidence of nausea and vomiting, weakness, and lethargy. Side effects usually appear within the first week of starting the drug but fortunately many are transient and subside on continued medication. The incidence of side effects correlates with body weight of the patients; probably many side effects may be avoided in future by reducing dosage.

Unlike most trials on beta-blocking agents, this study was undertaken without a "run-in" period in which to determine the maximal effective dose. This has the advantage of removing built-in bias towards the drug that such a run-in will produce, but it also means that the optimal dosage is not necessarily achieved.

Though the code was never broken until the end of the study, in some instances the relief of angina was so dramatic and in others the side effects were so definite that both patient and doctor strongly suspected that they could distinguish perhexiline from placebo. The former, at least, is an unavoidable aspect of any study in which a drug is assessed for its efficacy in preventing pain and is found to be successful.

Laboratory studies were made on all patients in this trial and in other trials previously reported. No abnormalities were found in tests of haematological or renal function nor in serum electrolytes, cholesterol, or blood glucose. In the United States no consistent trends of abnormalities have been reported in liver function tests, but in three of the four centres here some rises in SGOT levels were seen. Unlike the subjective side effects, these biochemical abnormalities did not appear soon-in most patients only after three to four weeks' therapy. All these patients remained well and asymptomatic.

We consider that perhexiline is a valuable drug for treating angina and is particularly useful in: (1) patients with severe angina and especially those who have failed to respond to other antianginal drugs, notably beta-blockers; many patients in this trial had been previously treated unsuccessfully with betablockers and long-acting nitrates before successful therapy with perhexiline; (2) patients in whom the resting heart rate is slow enough for beta-blockade to be considered dangerous; and (3) patients in whom bronchospasm is a problem; Feinsilver et al. (1970) showed that perhexiline caused bronchodilatation in asthmatic patients. Though practolol has little bronchospastic action, no antianginal drug other than perhexiline has a bronchodilator effect.

Perhexiline may also be safer to use than beta-blocking agents in patients with congestive heart failure.

We are grateful to Dr. J. P. Birkett, of Richardson-Merrell Limited, for advice and for the supplies of perhexiline maleate and placebo tablets used in the study.

Requests for reprints should be sent to Dr. C. J. Burns-Cox, Department of Medicine, Frenchay Hospital, Bristol BS16 1LE.

\section{References}

Cho, Y. W., Belej, M., and Aviado, D. M. (1970). Chest, 58, 577.

Feinsilver, O., Cho, Y. W., and Aviado, D. M. (1970). Chest, 58, 558

George, C. G., Nagle, R. E., and Pentecost, B. L. (1970). British Medical fournal, 2, 402.

Gillam, P. M. S., and Prichard, B. N. C. (1965). British Medical Fournal, 2 , 337.

Grupp, I. L., Bunde, C. A., and Grupp, G. (1970). Fournal of Clinical Pharmacology and Fournal of New Drugs, 10, 312

Hirshleifer, I. (1969). Current Therapeutic Research, 11, 99.

Hudak, W. J., Lewis, R. E., and Kuhn, W. L. (1970). Fournal of Pharmacology and Experimental Therapeutics, 137, 371 .

Keelan, P. (1965). British Medical fournal, 1, 897.

Lyon, L. J., Nevins, M. A., Fisch, S., and Henry, S. (1971). Lancet, 1, 1272. Martins de Oliveira, J., and de Almeida Amado, N. J. (1970). Hospital (Rio de faneiro), 77, 1511.

Wilson, D. F., Watson, O. F., Peel, J. S., and Turner, A. S. (1969). British Medical fournal, 2, 155.

Winsor, T. (1970). Clinical Pharmacology and Therapeutics, 11, 85.

\title{
Effect of Resection of Lung Tumours on the Steroid Abnormalities in Patients with Lung Cancer
}

\author{
L. G. S. RAO
}

British Medical fournal, 1971, 4, 588-590

\section{Summary}

The urinary excretion of androsterone, aetiocholanolone, total 17-oxosteroids, and 17-hydroxycorticosteroids (17OHCS) was measured in 40 patients with lung cancer three days before resection and again 10-15 days after resection of their lung tumours. There was a significant postoperative increase in the excretion of 17-OHCS but a significant decrease in the excretion of androsterone and aetiocholanolone, resulting in an increase of the preoperative abnormalities in steroid excretion in these patients. Since there was no change in steroid excretion

Psychosomatic Research Unit, Department of Psychological Medicine, Southern General Hospital, Glasgow S.W.1

L. G. S. RAO, M.SC., PH.D., Research Fellow towards normal after resection of the lung tumours, it seems that the steroid abnormalities found in lung cancer are not the effect of the presence of the lung tumours. As the excretions of 17-OHCS and 11-deoxy17-oxosteroids change in opposite directions after resection, it is suggested that a dissociation of factors that control the excretion of these two groups of steroids takes place as a response to surgical stress in patients with lung cancer.

\section{Introduction}

Previous work from this laboratory (Rao, 1970) has shown that most patients with lung cancer show several abnormalities in the excretion of 17-oxosteroids (17-OS) and 17-hydroxycorticosteroids (17-OHCS). These abnormalities have been combined into discriminant function which seems to be of diagnostic and prognostic value (Rao, 1970; Rao and Hewit, 1970). The 